\title{
The optimal allocation of current assets using mean-variance analysis
}

\author{
Georgios Kolias ${ }^{\mathrm{a}, 1}$ and Nikolaos Arnis ${ }^{\mathrm{a}}$ \\ ${ }^{a}$ University of Ioannina, Greece
}

\begin{abstract}
Research Question: The investigation of the optimal allocation of current assets. Motivation: Current assets investment is a decision process which affects firm value. In this paper, we develop a framework that encompasses these decisions by taking into consideration the trade-off between risk and return. Idea: We build up a model implemented in two stages. In the first stage, using random coefficient modeling on panel data, we obtain the estimates of the expected returns and standard deviations for cash holdings, inventories and receivables along with the correlations between them. Having these estimates on hand we move on to the second stage to determine the optimal allocation of current assets portfolio and construct the efficient frontier of the possible combinations of the current assets' elements. Data: For the purposes of our study we use financial data from Greek manufacturing firms, drawn from their annual income statements and balance sheets. Firms are classified into the manufacturing industry for the years 2003 to 2014. Tools: In the first stage we use random coefficient modeling on panel data while in the second stage mean-variance analysis is employed. Findings: By applying the model in the Greek manufacturing sector we find that the minimum-variance portfolio of the average firm of our data set has an expected return of $10.00 \%$ with a $6.14 \%$ standard deviation (risk) and consists of $13 \%$ cash and cash equivalents, $29 \%$ inventories and $58 \%$ receivables. Contribution: Our model would be useful to assess and monitor firms' current assets investments and may be used in the formulation of sound current assets policies and procedures.
\end{abstract}

Keywords: Finance; Current assets management; Random coefficient modeling on panel data; Mean-variance analysis

\footnotetext{
${ }^{1}$ Corresponding author: School of Economics \& Administrative Sciences; Department of Accounting \& Finance; University of Ioannina; Campus Preveza; 48100 Greece; Tel: +30 268250556 email addresses: koliasg@ otenet.gr; narnis@teiep.gr
} 
JEL codes: C23, C61, G11, M41

\section{Introduction}

A certain amount of investment in working capital is necessary at any given point of time for the firm to run its normal operations. Working capital refers ${ }^{1}$ to the total investment in current assets and its policy involves the important issue of determining the appropriate level for each type of current assets. Current assets are composed of inventories of raw materials, work-in-progress inventory, finished goods inventory, accounts receivables and cash and cash equivalents. Receivables represent the amount of sales that have yet to be collected. Raw materials inventory represents the initial input which is necessary for the production process. Work-inprogress inventory represents items which appear in the next stage in production line but have not yet been converted into finished goods. Finished goods inventory comprises inventories that appear in the scheduled completed form, ready to be sold but which have not yet been sold to customers. All of these items have one common characteristic; they can be readily converted into cash, in contrast to long term assets that are less capable of being liquidated. Cash and cash equivalents can be regarded as their holder's 'inventory of the medium of exchange' (Baumol, 1952). Hence, not only inventories and receivables but even cash may be considered as an asset investment. Cash and cash equivalents are traditionally called cash holdings ${ }^{2}$, and are in fact corporate assets invested in cash or highly liquid, riskfree near-cash securities.

However, Duchin et al. (2017) find that about $40 \%$ of cash holdings, representing $6 \%$ of total book assets, are held in risky assets and about $80 \%$ of these assets are illiquid. In recent years the main focus of attention has been on the funds invested in current assets as well as on their performance. For example, CFO Magazine has been publishing annual rankings of firms since 1997 based on their working capital management performance calculated by using the latest publicly available data every year. The magazine published its first list of the 1000 largest companies in the United States across 35 industries while by 2012 it had been experienced with the 1,000 largest public companies across 57 industries (Filbeck et al., 2017). The ranking is based on working capital measures like days sales outstanding, days inventory outstanding and days payable outstanding.

In the annual Working Capital Management survey entitled 'All tied up', 2016, by EY (EY, 2016), the publication focuses on the top 2,000 companies in the US and Europe, examining their working capital performance at a company, regional, industry and country level. Thus, the question arising is if current assets being used to the maximum efficiency are consistent with the total business risk, the accessibility to fund resources and the sustainable growth of the firm. Answering 
this question presupposes that the complex and evolving trade-offs between the desired return and risk exposure are clearly understood and appropriately managed. Working capital management is a decision-making problem.

A possible framework takes into consideration that: a) cash, inventories and receivables may be evaluated in terms of profitability in which profits become expected returns under uncertain conditions; e.g., the contribution of the investment in each one of the current assets' components to total profits is evaluated under risk settings, b) the expected return of an asset is estimated concurrently with the anticipated returns of the other current asset investments made by the firm. For example, profitability of inventories will depend upon credit sales - which, in accounting terms, generate accounts receivables - profitability; cash management contribution to total earnings is affected by all other assets management decisions, and c) current assets are treated as combined items in a portfolio of asset investments, would be useful to assess and monitor firms' current assets investments and may be used in the formulation of sound current assets policies and procedures.

To apply such a framework, the estimation of the three following parameters is required; namely, the estimation of the expected return and the corresponding variance of the expected return of current assets components, as well as the estimation of correlation of the expected return among them. Therefore, our model design is implemented in two stages. In the first stage, using random coefficient modeling on panel data ${ }^{3}$, we obtain the estimates of the above three parameters. We point out that the expected return of each of the current assets is approximated by the contribution of the components to firm earnings. Having on hand these estimates we move to the second stage employing mean-variance analysis to determine the optimal allocation of current assets portfolio and construct the efficient frontier of the possible combinations of the current assets' elements. We find that the minimumvariance portfolio of the average firm of our data set has an expected return of $10.00 \%$ with a $6.14 \%$ standard deviation (risk) and consists of $12.97 \%$ cash and cash equivalents, $29.43 \%$ inventories and $57.60 \%$ receivables. Additionally, we calculate the portfolio with maximum mean-standard deviation ratio (the Tangency portfolio). The weights of this portfolio are $16.35 \%$ for cash and cash equivalents, $24.21 \%$ for inventories and $59.23 \%$ for receivables. The expected return at this point is $10.60 \%$ with a standard deviation of $6.32 \%$. The estimates of our model can be applied in performance analysis and decision-making process to benchmark a firm's current asset allocation to the optimum allocation of the average-firm of the same industry. Hence, the framework developed in this paper may help managers to improve efficiency of current assets management and thus to increase firm value.

The rest of this paper is organized as follows: In Section 2 we review the relevant literature. Section 3 summarizes the data and defines the variables used. In this section, we also discuss the econometric issues of the random coefficient model applied to derive the estimates of the returns, the variance and the correlations of 
current assets. Additionally, the mean-variance analysis is presented. Section 4 reports the results of the mean-variance framework on an empirical study of the current assets portfolio of Greek manufacturing firms. We conclude the paper in section 5 with a discussion of limitations and directions for future research.

\section{Literature review}

Early studies in finance ${ }^{4}$ have argued that in a world of perfect markets with no transaction and bankruptcy costs, where there are no delays in the production and supply chain and no differences in the borrowing rates among firms, the value of the firm does not depend on current assets decisions and there is no need for firms to hold current assets. However, it is clear that in the real word the conclusions reached by economic models based on the hypothesis of perfect markets do not seem to apply in practice. Not only do firms hold a substantial amount of current assets but financial managers seem to devote a vast amount of their business time to short term financial tasks (Gitman, 2005). Financial statement analysis literature supports disaggregating profitability into asset turnover and profit margin as a tool to measure diverse operations (Feltham \& Ohlson, 1995; Esplin et al., 2013). Fairfield and Yohn (2001) argue that disaggregating the change in return on assets into the change in assets turnover and the change in profit margin provides incremental information about firm's future profitability.

The changes in total amount of current assets influence the changes in total assets turnover which in turn has impact on firm's future profitability. Besides the amount, the composition of current assets that a firm should hold is also of great interest to managers and researchers alike. Moreover, it turns out that the proportion of each one of the current assets to total current assets varies widely across firms. The financial impact of these differences is significant because current asset policies affect the future returns of the company. For example, McGuinness et al. (2018) using data for SME of 13 European countries find that one standard deviation increase in trade credit results in a $21 \%$ decrease in the likelihood of distress. Box et al. (2018) provide evidence for better performance for firms that extend trade credit in excess of industry competitors with the financial characteristics.

Kieschnick et al. (2013) find a positive relationship between shareholder return associated with investments in working capital. Aktas et al. (2015) find that an optimal level of working capital exists and firms that converge to that optimal level improve their stock and operating performance. Zeidan and Shapir (2017) state that reductions in the cash conversion cycle should increase shareholder value. The general purpose of working capital management is to control the firms' current accounts to accomplish a desired balance between profitability and risk. Gentry (1988) describes a three-dimensional demonstration of the problem, based on 
Howard's framework (Howard, 1968), which set up the characteristics of the decision-making structure (space). The three dimensions of the space are the degree of uncertainty, the degree of time effect, and the degree of complexity represented by the number of the variables (factors) affecting the decisions.

Therefore, it is clear that models that embrace all the three dimensions of the problem will be more responsive to real situations. Working capital management as a decision-making problem can be integrated into this context. It is generally accepted that managing either individual current assets components or a combination of them or all of the current assets simultaneously, is linked to the process of maximizing the present value of firm cash flows ${ }^{5}$. Hence, one approach to determine the optimum level of working capital is to presume that when each component of working capital, i.e. inventories, cash and accounts receivables, is at their optimum level, then total working capital is at the optimal level too. However, current assets components are correlated with each other. The presence of correlation is another factor that adds to the complexity of the problem of current assets management. For these relationships many studies in accounting and operation literature have been consulted ${ }^{6}$.Thus, cash holdings, inventory and credit policies are interrelated and should be determined simultaneously; otherwise, isolating these policies could spawn fallible management decisions. To evaluate the impact of the contribution of current assets management to firm value, interrelations between the elements would have to be considered. Although there is a substantial amount of existing literature on cash management ${ }^{7}$, receivables management ${ }^{8}$ as well as inventory management ${ }^{9}$, few attempts have been made to integrate current assets management ${ }^{10}$.

This paper employs Portfolio theory ${ }^{11}$ techniques (or mean-variance optimization ${ }^{12}$ ) and focuses on the relation between risk and return of the investments in current assets and on the interrelationships among the components in order to arrive at their optimal allocation in current assets portfolio. So, for a desired current asset portfolio return, both the corresponding risk and asset allocation can be calculated or, alternatively, given the risk level the firm puts up with, the maximum expected return and the corresponding current asset allocation should be determined.

Our study will make a significant contribution to better investigating and identifying the optimal allocation of current assets and the results will contribute to strengthening future scientific research on business strategy and evaluation At this point we note that current assets allocation management goes after fixed assets decisions. Fixed assets decisions include the acquisition of such assets as land, buildings and equipment. Those investments must be consistent with and reinforce the firms' strategy and should be considered as long-term decisions that are not subject to revision in the short run. However, the linkage between short-run and longrun financial decision-making is unclear at best and nonexistent at worst (Maness \& Zietlow, 2005). Nevertheless, once the investments in fixed assets have been 
determined, short-term financial decisions that affect the amount of current assets' elements should be implemented.

\section{Data description - Model design}

For the purposes of our study we use financial data from Greek manufacturing firms, drawn from their annual income statements and balance sheets. Firms are classified into the manufacturing industry for the years 2003 to 2014. Our dataset contains 64,927 observations across 6,062 firms.

According to our data set for the period 2003 to 2014, current assets represent on average $65 \%$ of total assets while current asset turnover was 1.33 , meaning that these firms use, on average, 75 cents of current assets for each euro of sales. However, it is not their possession that denotes their significance; it is, mainly, their function. Their use in conjunction with the employment of fixed assets generates the firms' earnings; in our dataset, each euro invested in current assets produces, on average, 10.66 cents of EBITDA (Table1).

Table 1. Average Current assets futures for the period 2003-2014 for the Greek manufacturing sector.

\begin{tabular}{cccc}
\hline year & $\begin{array}{c}\text { Current assets } \\
\text { turnover }\end{array}$ & $\begin{array}{c}\text { Current assets to total } \\
\text { assets }\end{array}$ & $\begin{array}{c}\text { EBITDA to Current } \\
\text { assets }\end{array}$ \\
\hline 2003 & 1.45 & $65.75 \%$ & $13.15 \%$ \\
2004 & 1.55 & $64.62 \%$ & $14.88 \%$ \\
2005 & 1.44 & $65.48 \%$ & $12.91 \%$ \\
2006 & 1.40 & $66.86 \%$ & $12.91 \%$ \\
2007 & 1.38 & $67.54 \%$ & $12.44 \%$ \\
2008 & 1.39 & $66.39 \%$ & $11.74 \%$ \\
2009 & 1.22 & $65.86 \%$ & $9.58 \%$ \\
2010 & 1.23 & $66.12 \%$ & $8.19 \%$ \\
2011 & 1.21 & $65.75 \%$ & $6.37 \%$ \\
2012 & 1.20 & $65.43 \%$ & $5.92 \%$ \\
2013 & 1.23 & $65.35 \%$ & $8.70 \%$ \\
2014 & 1.27 & $65.92 \%$ & $10.67 \%$ \\
Total & & & \\
\hline
\end{tabular}

Cash and cash equivalents represent a portion of $15 \%$ of current assets with standard deviation of $16 \%$. Similarly, inventories account for $28 \%$, whilst receivables account for $57 \%$ of currents assets with a corresponding standard deviation of $21 \%$ and $22 \%$ respectively (Table 2). 
Table 2. Descriptive statistics of cash holdings, Inventories and receivables as parts of current assets.

\begin{tabular}{lccc}
\hline & $\begin{array}{c}\text { cash/ current } \\
\text { assets }\end{array}$ & $\begin{array}{c}\text { inventories/ current } \\
\text { assets }\end{array}$ & $\begin{array}{c}\text { receivables/ current } \\
\text { assets }\end{array}$ \\
\hline Mean & $14.60 \%$ & $28.39 \%$ & $57.00 \%$ \\
median & $8.43 \%$ & $24.66 \%$ & $58.59 \%$ \\
Std. Dev. & $15.93 \%$ & $20.52 \%$ & $21.71 \%$
\end{tabular}

Table 3 presents the correlation matrix between the levels of the current assets.

Table 3. Correlation matrix between the levels of current assets.

\begin{tabular}{cccc}
\hline & receivables & inventories & cash \\
\hline receivables & 1 & & \\
inventories & 0.72 & 1 & \\
cash & 0.38 & 0.36 & 1
\end{tabular}

Figure 1 shows a plot of the levels of cash, inventories and receivables over the years 2003-2014. It can be ascertained that there is a strong positive correlation between the levels of the current assets. Such correlations indicate the concurrent adjustment of cash holdings, inventories and receivables levels.

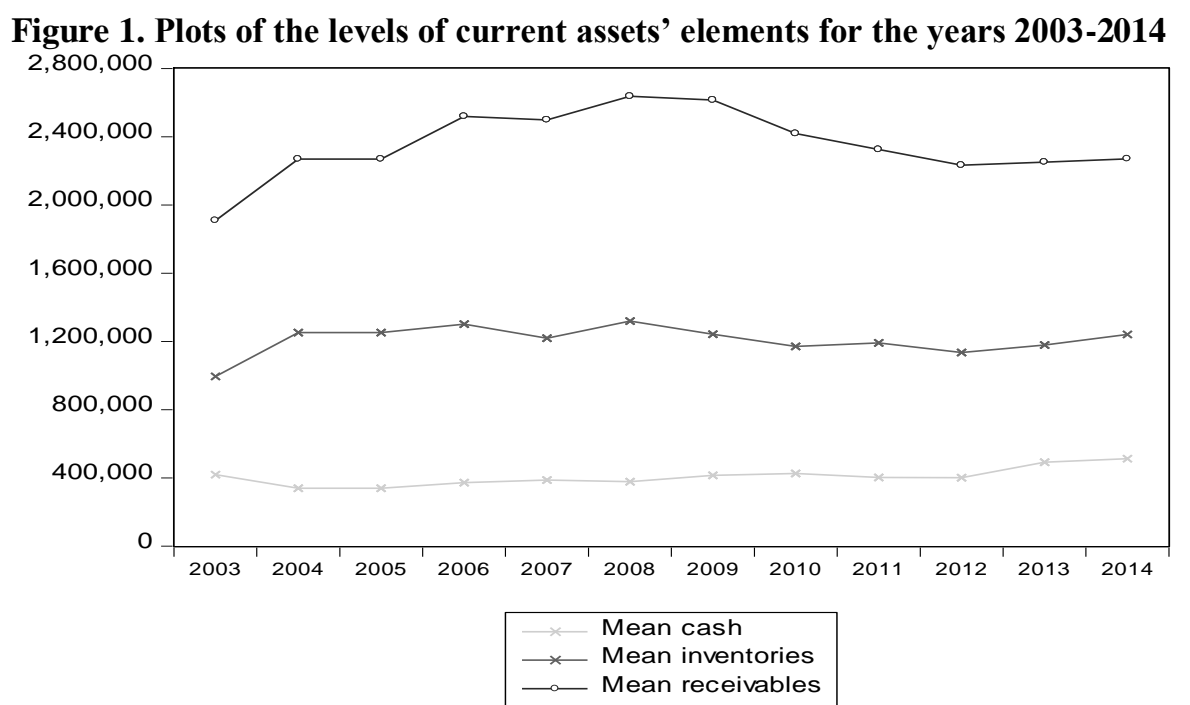

Table 4 presents the correlation matrix between the proportions of each one of the current assets to total current assets. 
Table 4. The correlation matrix of the proportions of current assets' elements to current assets for the years 2003-2014

\begin{tabular}{|c|c|c|c|}
\hline & $\begin{array}{l}\text { cash/cur.asse } \\
\text { ts }\end{array}$ & nventories/cur.Asset & $\begin{array}{l}\text { receivables/cur. } \\
\text { assets }\end{array}$ \\
\hline cash to current assets & 1 & & \\
\hline $\begin{array}{l}\text { inventories to current } \\
\text { assets }\end{array}$ & -0.31 & 1 & \\
\hline $\begin{array}{l}\text { receivables to current } \\
\text { assets }\end{array}$ & -0.44 & -0.72 & 1 \\
\hline
\end{tabular}

In Figure 2, the by-year mean of the proportion of cash, inventories and receivables to total current assets for the period 2003-2014 is plotted.

Figure 2. Plots of the proportions of current assets' elements to current assets for the years 2003-2014

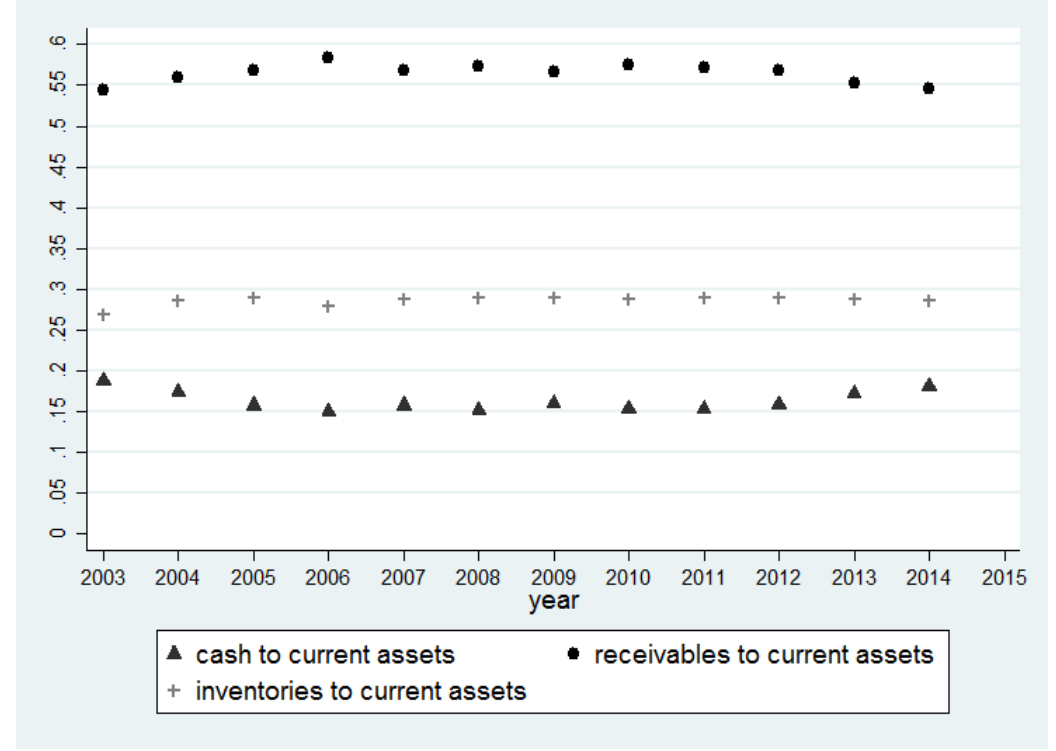

The plot as well as the correlation matrix show negative correlations between the elements of current assets, especially the one between inventories and receivables.

\subsection{Formulation and specification of the econometric model}

As mentioned above, our analysis is implemented in two stages. At the first stage we estimate the following model to derive estimates of the returns, variances and correlations of cash, inventories and receivables:

$$
\text { earnings }_{i t}=b_{1, i} \text { cash }_{i t}+b_{2, i} \text { invent }_{i t}+b_{3, i} \text { receiv }_{i t}+u_{i t}
$$


where index $i$ refers to the firm and $t$ measures time. The dependent variable earning $s_{i t}$ denotes earnings before interest, taxes, depreciation and amortization of firm $i$ in year $t$ :

earnings $_{i t}=E B I T D A_{\mathrm{it}}-\left(\right.$ taxes $_{i t}+$ interest payments $_{i t} \times$ marginal tax rate $\left._{t}\right)$

We chose this specification of firm earnings because we focus on current asset management and therefore: i) we shall hold constant fixed asset investments, and ii) we should be indifferent to the firm's capital structure. Thus, we calculate earnings before depreciation and amortization to adjust for fixed asset investments and we add back interest tax shields, the product of interest payments to marginal tax rate, assuming that all firms are all-equity financed.

The independent variables cash, invent and receiv denote the level of cash and cash equivalents, inventories and receivables, respectively. The error term $\boldsymbol{u}_{i t}$ captures idiosyncratic disturbances that vary over time as well as across firms. The $\boldsymbol{b}_{\boldsymbol{i}}$ 's denote the coefficients to be estimated. We estimate firm-wise coefficients and refer to that as model (1) assuming differences in current assets contribution to earnings among firms. Finally, we suppress constant term from the regression, taking into consideration the economic reality that with zero investments in current assets there is no activity in the short-run and, thus, no earnings gained for the firm.

We allow $\boldsymbol{b}_{\boldsymbol{i}}$ 's to vary across firms and treat them as random variables with common means plus a random part. In fact, we assume the presence of unobserved effects at firm level and, relaxing the assumption of homogeneity at firm level, we introduce random firm-specific slopes of the explanatory variables. The aim of our paper is to obtain the contribution of each one of the current assets to earnings, using them as inputs in the mean-variance optimization framework. This contribution is represented by the coefficients, $\boldsymbol{b}_{i}$, of the model.

However, the included conditional variables together with error components cannot completely capture systematic differences across firms. Besides, the possibility of including additional conditional variables is not an option, because our purpose is to keep the model as simple as possible. Therefore, in order to derive the estimates of the three coefficients, there is very little alternative but to allow the slope coefficients to vary across firms (Bresson et al., 2006 and Hsiao \& Pesaran, 2004).One possibility would be to treat $\boldsymbol{b}_{\boldsymbol{i}}$ 's as fixed and different. In this case, the modelis reduced to the Zellner's seemingly unrelated regression framework (Zellner, 1962).

However, in our study we view the different slope coefficients as random draws from a common population in order to make inferences on the population characteristics. In addition, we assume that variable coefficients are not correlated with the explanatory variables. Hence, a random-coefficient framework is plausible for the 
analysis of different coefficients of the explanatory variables across firms (Hsiao \& Pesaran, 2004). According to this notation $b_{i}$ 's can be written as follows:

$$
\begin{aligned}
& b_{1, i}=b_{1}+a_{1, i} \\
& b_{2, i}=b_{2}+a_{2, i} \\
& b_{3, i}=b_{3}+a_{3, i}
\end{aligned}
$$

where $b_{1}, b_{2}$ and $b_{3}$ represent the common means and $a_{k, i}(k=1,2,3)$ the random part with zero means and constant variances and covariances, uncorrelated with the explanatory variables as well as with the idiosyncratic disturbances $\left(\mathrm{u}_{\mathrm{sit}}\right)$.

Combining the above equations, (1) can be written as follows, representing a random coefficient model:

$$
\text { earnings }_{i t}=\left(b_{1} \text { cash }_{i t}+b_{2} \text { invent }_{i t}+b_{3} \text { receiv }_{i t}\right)+\left(a_{1, i} \text { cash }_{i t}+a_{2, i} \text { invent }_{i t}+a_{3, i} \text { receiv }_{i t}+u_{s i t}\right)
$$

Estimating model (1) we can obtain the estimates of returns, variances and covariances of current assets which can be used as inputs in the mean-variance optimization task at the next stage of our framework. More specifically, we can get empirical Bayes predictions of the mean firm-specific slopes which represent the expected returns of each asset:

$$
\text { eârnings } s_{i t}=\hat{b}_{1} \text { cash }_{i t}+\hat{b}_{2} \text { invent }_{i t}+\hat{b}_{3} \text { receiv }_{i t}
$$

At the same time, we can get the estimated variances and covariances of the slopes. Let $Q$ be the $3 \times 3$ covariance matrix:

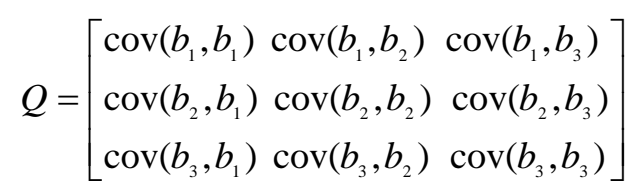

Notice that the covariance matrix is symmetric (the elements off the diagonal are equal):

$$
\operatorname{Cov}(i, j)=\operatorname{Cov}(j, i) \quad \text { so, } Q(i, j)=Q(j, i) \forall i \neq j, \text { where } i, j=\left(b_{1}, b_{2}, b_{3}\right)
$$

Moreover, the diagonal elements are equal to the variance of assets: $\operatorname{Cov}(i, i)=\sigma_{i}^{2}$ 


\subsection{The Mean-variance analysis}

At the second stage, we apply mean-variance analysis using the results obtained at the first stage. The set of the efficient portfolios is defined as portfolios that maximize the expected return for the given risk (represented by the standard deviation of the return), or the portfolios that minimize the risk subject to a given expected return (Fabozzi et al., 2002).

To begin, let $\boldsymbol{w}$ be the vector of the weights of each asset in the portfolio of current assets, $\boldsymbol{r}$ the vector of returns and $\boldsymbol{\imath}$ an identity $3 \times 1$ vector:

$$
w=\left[\begin{array}{l}
w_{\text {cash }} \\
w_{\text {ivvent }} \\
w_{\text {receiv }}
\end{array}\right] \quad r=\left[\begin{array}{l}
b_{1} \\
b_{2} \\
b_{3}
\end{array}\right] \quad l=\left[\begin{array}{l}
1 \\
1 \\
1
\end{array}\right]
$$

The expected return on the portfolio is

$$
\begin{array}{lr}
\text { The expected return on the portfolio is } & E\left(R_{P}\right)=r^{T} w \\
\text { The variance of the portfolio return is } & \sigma_{\rho}^{2}=w^{T} Q w
\end{array}
$$

Let $m$ be the required portfolio return and considering that the weights of current assets sum to one, we have:

$$
r^{T} w=m \text { and } \sum_{i=1}^{3} w_{i}=1 \text { or } t^{T} w=1
$$

Thereafter we ask for:

$$
\operatorname{Min}\left\{w^{T} Q w \mid r^{T} w=m, \imath^{T} w=1\right\}
$$

The solution gives the expression for the efficient frontier in risk-return framework. Merton (1972) has proved that in the mean-standard deviation plane the efficient frontier is represented by the part of a hyperbola. Qi et al. (2017) state that the meanvariance model is a bi-criterion optimization problem deals with variance minimization and expected return maximization.

At this point, it is worthy of note that we should have imposed a non-negativity restriction, namely $w>0$, to the problem, because in this task negative values for any of the current assets are not meaningful. Thus, the problem is defined as follows:

$$
\operatorname{Min}\left\{w^{T} Q w \mid r^{T} w=m, l^{T} w=1, w>0\right\}
$$

The addition of this non-negativity constraint prevents negative values of the weights. The problem now becomes a quadratic programming problem ${ }^{13}$. We note 
that there are standard packages available for solving quadratic problems. So, (2) it is easy to be solved.

Furthermore, for the purposes of our study it is important to calculate two specific portfolios, the minimum variance portfolio and the tangency portfolio. We will use them as the recommendations and benchmarks for an adequate current asset management. The minimum variance portfolio is a portfolio on the efficient frontier with the global minimum variance. At this point, the standard deviation also- let it be, $\sigma_{\mathrm{mv}}-$ is minimal. The tangency portfolio is the portfolio with maximum Sharpe ratio (Sharpe, 1966, 1994). Sharpe ratio is defined as the maximized mean to standard deviation ratio (or return-risk ratio) and represents the marginal change in expected return with respect to marginal changes in risk, while its purpose is to evaluate the skills of a particular strategy. The tangency portfolio corresponds to the point where a line through the origin in mean - standard deviation plane is tangent to the efficient frontier that stands for the highest return-risk ratio.

\section{Results}

\subsection{Results of the random coefficient model}

Table 5 shows the fit statistics for model (1) using random coefficient estimates for panel data.

Table 5. Results of model (1)

\begin{tabular}{lrrrr}
\hline Depended variable: earnings & & & & \\
\hline \multicolumn{1}{c}{ A. Coefficient estimates } & \multicolumn{1}{c}{ Coef. } & Std. Err. & \multicolumn{1}{c}{ z } & p-values \\
cash & 0.173 & 0.013 & 13.54 & 0.000 \\
invent & 0.040 & 0.008 & 5.26 & 0.000 \\
receiv & 0.114 & 0.004 & 26.63 & 0.000 \\
$\quad$ B. Random-effects Parameters & Estimate & Std. Err. & {$[95 \%$ Conf. Interval] } \\
var(cash) & $7.96 \%$ & $0.60 \%$ & $6.88 \%$ & $9.22 \%$ \\
var(invent) & $3.87 \%$ & $0.24 \%$ & $3.41 \%$ & $4.38 \%$ \\
var(receiv) & $1.56 \%$ & $0.09 \%$ & $1.40 \%$ & $1.74 \%$ \\
cov(cash,invent) & $-0.10 \%$ & $0.28 \%$ & $-0.65 \%$ & $0.45 \%$ \\
cov(cash,receiv) & $-1.09 \%$ & $0.17 \%$ & $-1.41 \%$ & $-0.76 \%$ \\
cov(invent,receiv) & $-1.30 \%$ & $0.12 \%$ & $-1.53 \%$ & $-1.06 \%$ \\
\hline
\end{tabular}

All of the coefficients are found positive and statistically significant, as we expected, because of the structure of the model. More specifically, we have regressed the level of earnings on the level of each one of the current assets. Therefore, considering that 
all of the current assets are well thought-out and necessary for the firm to operate, then, by definition, all of them contribute to firm earnings. Thus, we expected positive values for the coefficients. There are also academic studies confirming the negative relationship of gross margin and inventory turnover ratio (positive for the level of inventories) (Gaur et al., 2005; Kolias et al., 2011).

Besides, empirical studies provide evidence for the positive association between receivables and gross margin. For example, Barrot (2016) argues that the larger a firm's gross profit margin, the greater its receivables over sales. Hence, we can link the results of inventory and receivables policies through a common factor; the gross margin in this occasion. Thus, considering the correlation between inventories and receivables with gross margin -positive for the level of inventories and positive for receivables-we can expect positive effect of inventories and receivables on firm returns. Nevertheless, the point is, and this is what can serve our purpose, to what extent cash holdings, inventory and receivables contribute to earnings.

On the other hand, subsequent estimates of the random effects parameters, especially those of covariances (or correlations) - presented at section B of the table - are somewhat not as conventional (not easily hypothesized) as the estimates of the coefficients. All of them (variances and covariances) but one (the correlation between cash and inventories returns) are statistically significant. Considering the negative sign of the estimations of the pair-wise correlations, we conclude that the return of each one of the current assets is negatively related with the return of the other. Although it is hard to provide justification for the correlations, especially between cash effect and the effects of the other two assets on firm returns, we will examine those relationships in the following subsections.

\subsubsection{Correlations between cash effect and inventories effect on firm returns}

The magnitude of cash balances during the cash conversion ${ }^{14}$ cycle of the firm is composed of the cash balance at the beginning of the cycle and the net cash flows determined by a company's day-to-day business activities. Supposing that, even in the short run, the cash position is under the control of the firm's management, then firms adjust cash balances mainly for the following reasons: 1) to smooth the progress of daily payments of variable inputs (transaction motive), 2) to preserve the firm against negative cash flow shocks (precautionary motive) and 3) to take advantage of short-term investing opportunities (speculative motive).

Morris (1983) argues that cash balance should be expanded up to the point where the marginal value of the costs associated with cash management is equal to the return on the assets investments. Opler et al. (1999) -based on arguments similar to the pecking order and trade-off theory of capital structure-suggest that firms either trade off the costs and benefits of corporate liquidity to derive its optimal level or prioritize their sources of financing from internal financing to debt issuing and, eventually, to 
equity issuing, seeing debt and cash merely as the opposite sides of the same coin. Therefore, firms have a built-in preference to use internal to external financing in case they do (or they should) repay debt and accumulate cash otherwise. Additionally, they note that by controlling for dividend and investment policy, firms with higher returns on assets built up higher cash position.

Ozkan and Ozkan (2004) state that firms with greater growth opportunities are more likely to build up cash in order to have financial flexibility as well as to avoid costly external financing. All in all, cash balance, either being viewed as a current asset or as a means to acquire any other asset, is the regulating factor of actual inflows and outflows. In the short run, cash balances fall only in case that the firm intends (or may be forced) to invest in more profitable account receivables or inventories. Thus, it may be argued that the actual value and consequently the contribution of the transactions, precautionary and speculative cash balance to earnings is negatively correlated with the value of the investment in receivables and inventories.

Therefore, there seems to be no better choice for the firm than to maintain, in any case, large cash balances (cash plus cash equivalents) at the expense of the other current assets balances. Duchin et al. (2016) argue that if managers are able to earn excess risk-adjusted returns by investing the firm's cash holdings in risky assets, they are, obviously, creating value for the shareholders by presuming positive net present value. However, this decision would convert the firm from being, e.g., a manufacturer to being a holding company. So, the firm will consider current asset allocation only in an acceptable range determined by its economic activity.

\subsubsection{Correlations between inventories effect and receivables effect on firm returns}

The interrelationship between inventory policy and account receivables policy is well known and has been investigated, academically, since decades ago. Earlier, Schiff and Lieber (1974) presented an integrative dynamic model for inventory and account receivables model and stated that the variation of demand overtime causes production and credit decisions to shift the inventory and receivables levels to the opposite direction. These changes tend to smooth the fluctuations in the demand. Kim and Chung (1990) suggest a method of integrated evaluation of investments in inventories and receivables predicted on the basis of net present value maximization approach. They state that as soon as inventory and credit policy are considered independently, suboptimal results will become apparent. Furthermore, they claim that, ceteris paribus, the higher the profit margin the lower the optimal batch sales volume. 


\subsection{Mean-variance analysis}

To apply the mean-variance analysis, the estimation of expected returns and standard deviations for all available assets along with the correlations among them is required. These data can be used as an input into the optimizing process forming the set of optimal portfolios or the so-called efficient frontier.

Tables 6 and 7 below present the variance-covariance matrix, the expected returns and the variances of cash, inventories and receivables.

Table 6. Variance -Covariance -Correlation matrix of the expected returns of current assets.

\begin{tabular}{cccc}
$\mathbf{Q}$ & cash & invent & receiv \\
\hline cash & $\mathbf{7 . 9 6 \%}$ & -0.019 & -0.308 \\
invent & $-0.10 \%$ & $\mathbf{3 . 8 7 \%}$ & -0.528 \\
receiv & $-1.09 \%$ & $-1.30 \%$ & $\mathbf{1 . 5 6 \%}$ \\
Into the upper triangular part of the matrix the correlations are presented while the lower triangular shows the \\
\multicolumn{4}{c}{ covariances. }
\end{tabular}

Comparing the correlations in Table 6 we can conclude that the relation between the returns of inventories and receivables is significantly higher than that between cash and inventories or cash and receivables.

Table 7. Returns (r) and standard deviations ( $\sigma)$ of current assets

\begin{tabular}{ccc}
\hline & $\mathbf{r}$ & $\boldsymbol{\sigma}$ \\
\hline cash & $17.25 \%$ & $28.221 \%$ \\
invent & $4.00 \%$ & $19.663 \%$ \\
receiv & $11.44 \%$ & $12.497 \%$
\end{tabular}

Table 7 shows a remarkably lower return of inventories (4\%) with a corresponding high standard deviation (20\%), while cash return is perceived to be the highest $(17.25 \%)$ with a relatively higher standard deviation $(28.22 \%)$. Soon afterwards, using quadratic programming we are able to construct the efficient frontier (Figure 3 ) as well as to define the features of the minimum variance portfolio and the tangency portfolio (Table 8). 
Figure 1. Graphical presentation of the efficient frontier, minimum variance and tangency portfolio in return-standard deviation plane.

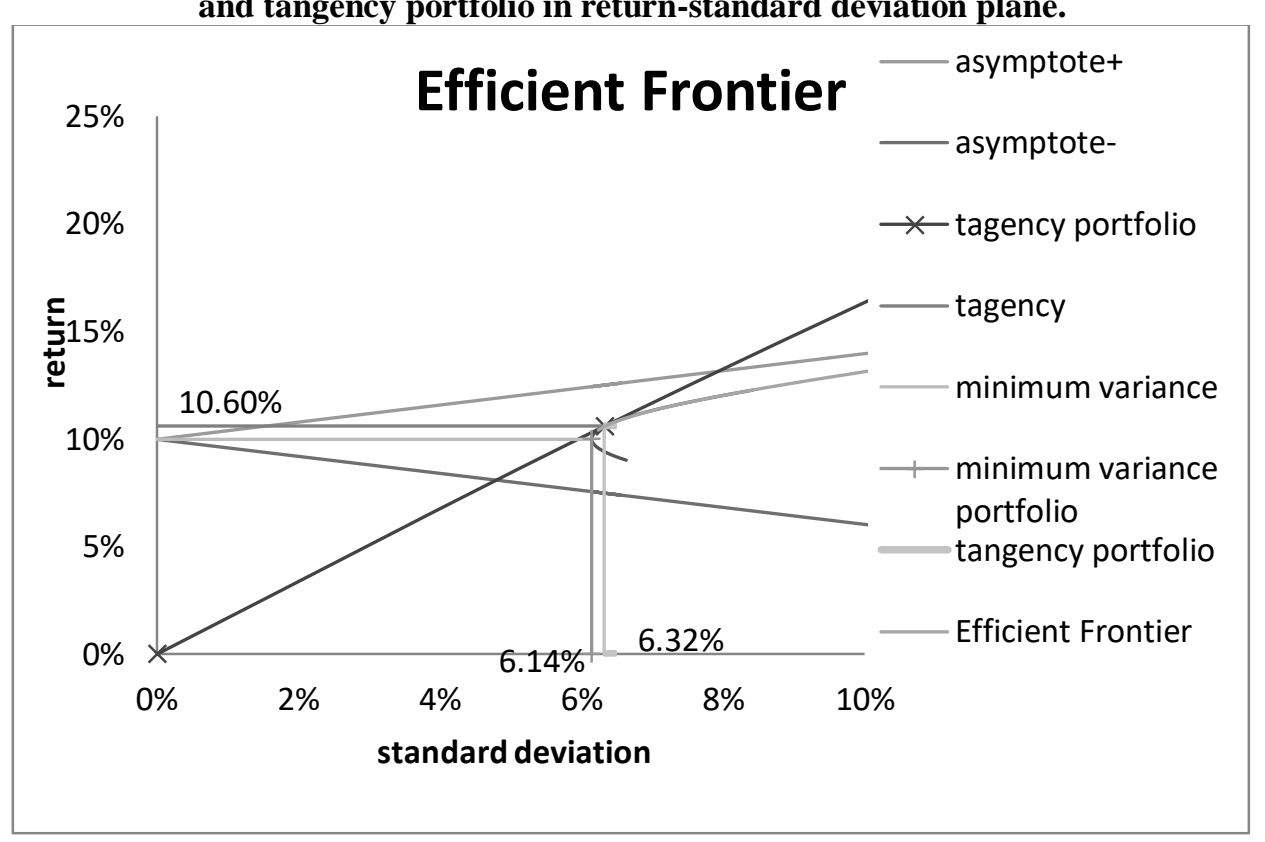

The graphical interpretation of the Minimum Variance and Tangency portfolios is also shown in figure 1 . The efficient frontier starts from the point represented by the minimum variance portfolio, and moving up to the northeast of the graph, the tangency portfolio is met at the point where a line through the origin is tangent to.

The standard deviation of the Minimum Variance portfolio is $6.14 \%$. At this point, the expected return is $10 \%$.The allocation of the portfolio assets is: $12.97 \%$ cash, $29.43 \%$ inventories, and $57.60 \%$ receivables (Table 8, part A). Tangency portfolio also lies on the efficient frontier and the expected return at this point is $10.60 \%$, with standard deviation $6.32 \%$ (Table 8, part B). The weights of the portfolio are $16.55 \%$ for cash, $24.21 \%$ for inventories and $59.23 \%$ for receivables (Table 8, part B). The tangency portfolio has the property of the maximization of mean-standard deviation ratio. As we have already mentioned, this portfolio represents the maximum of marginal change in expected return with respect to marginal changes in risk. In other words, it is the portfolio that generates the highest return for every unit of risk taken. So, its purpose is to evaluate whether a particular strategy of current asset allocation is in accordance with the best practices followed by the firms in the same industry. Both suggested portfolios represent the practice of the average firm, which either desires to invest in a portfolio with the least amount of risk (the case of minimum variance portfolio) or desires to invest in the most risk-effective portfolio (the case of tangency portfolio). 
Table 8. Minimum variance and tangency portfolio features

\begin{tabular}{|c|c|c|c|c|}
\hline \multirow{8}{*}{ B. } & & & \\
\hline & \multirow{3}{*}{$\begin{array}{c}\mathrm{r}_{\mathrm{mv}} \\
\mathbf{1 0 . 0 0 \%}\end{array}$} & \multirow[t]{3}{*}{$\begin{array}{c}\sigma_{\mathrm{mv}} \\
6.14 \%\end{array}$} & $\begin{array}{c}W_{\text {mv }} \\
12.97 \%\end{array}$ & $\begin{array}{l}\text { assets } \\
\text { cash }\end{array}$ \\
\hline & & & $29.43 \%$ & invent \\
\hline & & & $57.60 \%$ & receiv \\
\hline & \multicolumn{4}{|c|}{ Tangency portfolio } \\
\hline & \multirow{3}{*}{$\begin{array}{c}r_{t g} \\
\mathbf{1 0 . 6 0 \%}\end{array}$} & $\sigma_{t g}$ & $\begin{array}{c}W_{t g} \\
0\end{array}$ & assets \\
\hline & & & $\begin{array}{l}10.55 \% \\
24.21 \%\end{array}$ & invent \\
\hline & & & $59.23 \%$ & receiv \\
\hline
\end{tabular}

The designation of the efficient frontier also helps firms to understand where they fall on this line. The corresponding optimal asset allocation of the average firm may be applicable to a specific firm within an industry so as to yield similar returns, considering the risk level undertaken. This relative position informs firms if they remain 'efficient' with respect to their capital budgeting and to their ideal current assets structure.

\section{Conclusion, limitations of the study and directions for future research}

In this paper, we build up a model based on the fundamental principle of the Portfolio theory stating that a portfolio is mean-variance efficient if it maximizes the expected return among all other portfolios with the same standard deviation of returns or minimizes the standard deviation of returns among all those with the same expected return. The formulation of the model requires the estimates of the return and the risk of current assets. Therefore, our model design is implemented in two stages. First, we use random coefficient modeling on panel data to obtain the estimates of the contribution of cash holdings, inventories and receivables to earnings. Then, using those estimates as inputs we employ mean-variance analysis to determine the optimal allocation of current assets portfolio. So, for a desired current asset portfolio return both the corresponding risk and asset allocation can be addressed.

We focus on two definite portfolios, the minimum variance portfolio and the tangency portfolio. The features of these portfolios, i.e. the risk, the return and the allocation, can be used in performance analysis and enable comparison between a specific firm's current assets' allocation and the allocation of the average firm of the same industry proposed by our model. Hence, the framework developed in this paper may help managers to improve efficiency of current assets management and, therefore, to increase firm value. 
However, our model is based on the estimations of the parameters of a regression model that approximate the return, the risk and covariance matrix. Although we recognize that these attributes, in general, are hard to obtain, the employment of random coefficient techniques is the most adequate methodology for this case.

Moreover, our model is based on the traditional approach of the determination of portfolio choice by the first two moments of the distribution of the returns, namely the mean and the standard deviation. Although a discussion about the issue of whether higher moments should be considered in portfolio selection framework is completely out of the purpose of our study, the addition of the third moment, or skewness, into a general mean-variance analysis (see, e.g. Samuelson, 1970 or Kraus \& Litznberger, 1976) can be used in future research. Finally, a related research question may well be about capital structure. Our model, therefore, could be applied to investigate the optimal capital asset allocation.

\section{References}

Aktas, N., Croci, E., \& Petmezas, D. (2015) "Is working-capital management valueenhancing? Evidence from firm performance and investments", Journal of Corporate Finance, vol. 30: 98-113

Almeida, H., Campello, M., Cunha, I., \& Weisbach, M., (2014) "Corporate Liquidity Management: A Conceptual Framework and Survey", Annual Review of Financial Economics, Annual Reviews, vol. 6, no. $1: 135-162$

Arcelus, F.J., \& Srinivasan, G., (1994) “Integrating working capital decisions", The Engineering Economist, vol. 39, no. : 1-15

Barrot, J. N. (2016) "Trade credit and industry dynamics: Evidence from trucking firms", The Journal of Finance, vol.71, no. 5: 1975-2016

Bates, T., Kahle, K., \& Stulz, R., (2009) "Why Do U.S. firms hold so much more cash than they used to?", Journal of Finance, vol. 64, no. 5: 1985-2021

Baumol, W.J., (1952) "The transaction demand for cash: An inventory theoretic approach", Quarterly Journal of Economics, vol. 66: 545-556

Bolton, P., Chen, H., \& Wang., N. (2011) "A unified theory of Tobin's q, corporate investment, financing, and risk management", The Journal of Finance, vol. 66, no. 5: $1545-1578$

Box, T., Davis, R., Hill, M., \& Lawrey, C. (2018) "Operating performance and aggressive trade credit policies". Journal of Banking \& Finance, vol. 89, 192-208

Bresson, G., Hsiao, C. \& Pirotte, A. (2006) "Heteroskedasticity and random coefficient model on panel data", Working Papers ERMES 0601, ERMES, University Paris 2. 
Brigham, E., \& Ehrhardt, M. (2005) "Financial Management: Theory and Practice", 11th ed., South-Western, Thomson Co.

Chiang, A., \& Wainwright, K. (2005) Fundamental Methods of Mathematical Economics, $4^{\text {th }}$ ed., McGraw-Hill Co, Inc.

Chung, K., \& Lin, S. (1998) "Technical note-Determination of optimal procurement policy under integrating working capital", The Engineering Economist, vol. 43, 269-277.

Courakis, A. (1988) "Modeling portfolio selection”, The Economic Journal, vol. 98, no. 392: 619-642

Duchin, R., Gilbert, T., Harford, J., \& Hrdlicka, C. (2017) "Precautionary savings with risky assets: When cash is not cash", The Journal of Finance, vol. 72 , no. $2: 793-852$

Elton, E., Gruber, M., Brown, S., \& Goetzmann, W. (2003) Modern Portfolio Theory and Investment Analysis, $6^{\text {th }}$ ed., John Wiley and Sons, Inc.

Esplin, A., Hewitt, M., Plumlee, M., \& Yohn, T. L. (2014) "Disaggregating operating and financial activities: Implications for forecasts of profitability", Review of Accounting Studies, vol. 19(1), 328-362

EY (2016) All tied up. Working capital management report 2016. EY

Fairfield, P. M., \& Yohn, T. L. (2001) "Using asset turnover and profit margin to forecast changes in profitability", Review of Accounting Studies, vol. 6: 372-386

Feltham, G. A., \& Ohlson, J. A. (1995) "Valuation and clean surplus accounting for operating and financial activities", Contemporary Accounting Research, vol. 11: 689-731

Ferris, S. J. (1981) “A transaction theory of trade credit use”, Quarterly Journal of Economics, vol. 96: 243-270

Filbeck, G., Zha, X., \& Knoll R. (2017) "An analysis of working capital efficiency and shareholder return", Review of Quantitative Finance and Accounting, vol. 48: 265-288

Gallinger, G., \& Infflander, A. (1986) "Monitoring accounts receivables using variance analysis", Financial Management, vol. 15: 69-76

Gaur, V., Fisher, M., \& Raman, A. (2005) "An econometric analysis of inventory turnover performance in retail services", Management Science, vol. 51, no. 2: $181-194$

Gentry, J. (1988) "State of the art of Short-Run Financial Management", Financial Management, vol. 17, 41-56

Gentry, J., \& De La Garza, J. (1985) “A generalized model for monitoring accounts receivables", Financial Management, vol. 14: 28-38

Gentry, J., \& Lee, H.W. (1986) “An integrated cash flow model of the firm”, Faculty Working paper, University of Illinois.

Gitman, L. (2006) Principles of Managerial Finance, 11th ed., Pearson Education, Inc. 
Gupta, F., \& Eichhorn, D. (1998) "Mean-variance optimization for practitioners of asset allocation", In Fabozzi, F. (Ed.), Handbook of Portfolio Management, New York: John Wiley \& Sons, pp. 57-74

Howard, R. (1968) "The foundations of decision analysis", IEEE Transactions of on Systems Sciences and Cybernetics, vol. 4, no.3: 211-219

Hsiao, C. (2003) Analysis of panel data, $2^{\text {nd }}$ ed., Cambridge University Press.

Hsiao, C., \& Resaran, H. (2004) "Random coefficient panel data models", Discussion Paper No 12363.

Kieschnick, R., Laplante, M., \& Moussawi, R. (2013) "Working capital management and shareholders' wealth", Review of Finance, vol. 17, no.5: 1827-1852

Kim, C., Mauer, D., \& Sherman, A. (1998) "The determinants of corporate liquidity: Theory and Evidence", Journal of Financial and Quantitative Analysis, vol. 33: 335-359

Kim, Y. H., \& Chung, K. H. (1990) "An integrated evaluation of investment in inventory and credit: A cash flow approach", Journal of Business Finance \& Accounting, vol. 17: 381-390

Kim, Y., \& Atkins, J. (1978) "Evaluating investments in accounts receivables: A maximizing framework", Journal of Finance, vol. 33: 403-412

Kolias, G., Dimelis, D., \& Filios, V. (2011) "An empirical analysis of inventory turnover behavior in Greek retail sector: 2000-2005", International Journal of Production Economics, vol. 133, no.1: 143-153

Kraus, A. \& Litzenberger, R. (1976) "Skewness preference and the valuation of risky assets", Journal of Finance, vol. 21: 1085-1094

Lewellen, W., \& Edmister, R. (1973) "A General Model for Accounts Receivables and Control", Journal of Financial and Quantitative Analysis, vol. 8: 195-206

Lieber, Z., \& Orgler, Y. (1975) "An integrated model for accounts receivable", Management Science, vol. 22: 212-219

Maness, T., \& Zietlow, J. (2005) Short-term financial management, South-Western, Thomson Co.

Markowitz, H. (1952) "Portfolio selection", Journal of Finance, vol. 7: 77-91

McGuinness, G., Hogan, T., \& Powell, R. (2018) "European trade credit use and SME survival", Journal of Corporate Finance, vol. 49: 81-103

Merton, R. (1972) "An analytic derivation of the efficient frontier", Journal of Finance and Quantitative Analysis, vol. 7: 1851-1872

Mian, S., \& Smith, C., (1992) "Accounts receivable management policy: theory and evidence", Journal of Finance, vol. 47: 169-200

Miller, M., \& Orr, D., (1966) "A model of the demand for money by firms", Quarterly Journal of Economics, vol. 80: 413-435

Morris, J.R. (1983) "The role of cash balances in firm valuation", Journal of Financial and Quantitative Analysis, vol. 18: 533-545

Mulligan, C.B. (1997) "Scale economies, the value of time, and the demand for money: longitudinal evidence from firms", Journal of Political Economy, vol. 105: 1061-1079 
Opler, T., L. Pinkowitz, L., Stulz, R. \& Williamson, R. (1999) “The determinants and implications of cash holdings", Journal of Financial Economics, vol. 52: $3-46$

Ozkan, A., \& Ozkan, N. (2004) "Corporate cash holdings: An empirical investigation of UK Companies", Journal of Banking and Finance, vol. 28: 2103-2134

Qi, Y., Steuer, R. E., \& Wimmer, M. (2017) “An analytical derivation of the efficient surface in portfolio selection with three criteria", Annals of Operations Research, vol. 251, no. (1-2): 161-177

Richards, V., \& Laughlin, E. (1980) "A cash conversion cycle approach to liquidity analysis", Financial Management, vol. 9: 32-38

Samuelson, P., (1970) "The fundamental approximation theorem of portfolio analysis in terms of means, variances, and higher moments", Review of Economic Studies, vol. 37: 537-542

Sartoris, W., \& Hill, N. (1983) "A generalized cash flow approach to short term financial decisions", Journal of Finance, vol. 38: 349-360

Schiff, M., \& Lieber,Z. (1974) "A model for the integration of credit and inventory management", Journal of Finance, vol. 24: 133-140

Sharpe, W. (1966) "Mutual fund performance", Journal of Business, vol. 39 no. 1: $119-138$

Sharpe, W. (1994) "The sharpe ratio", The Journal of portfolio Management, vol. 21, no.1: 49-58

Stickney, C., \& Brown, P. (1999) Financial Reporting and statement analysis, $4^{\text {th }}$ ed. New York: Harcourt, Brace \& Co.

Stone, B. K. (1972) "The use of forecasts and smoothing in control-limit models for cash management", Financial Management, vol. 1: 72-84

Van Horne, J. (1969) "A risk-return analysis of a firm's working capital position", The Engineering Economist, vol. 14: 71-89

Yardeni, E., (1978) "A portfolio-balance model of corporate working capital", Journal of Finance, vol. 33: 535-552

Zeidan, R., \& Shapir, O. M. (2017) "Cash conversion cycle and value-enhancing operations: Theory and evidence for a free lunch", Journal of Corporate Finance, vol. 45, 203-219

Zellner, A. (1962) "An efficient method of estimating seemingly unrelated regressions and tests for aggregation bias", Journal of the American Statistical Association, vol. 57: 348-368

Zipkin, P. (2000) Foundations of Inventory Management, McGraw-Hill/Irwin Publishers, New York 
${ }^{1}$ According to the related literature (see, e.g., Brigham \& Ehrhardt, 2005) the problem of working capital management refers to its structure and its volume point of view. However, two relative definitions exist: 'Working capital'(or gross working capital) and 'Net working capital'. Net working capital is defined as current assets minus current liabilities. Working capital simply refers to current assets used in operations.

2 In this paper, the terms 'cash and cash equivalents' and 'cash holdings' are used interchangeably.

${ }^{3}$ For an analytic presentation of variable-coefficient models see, e.g., Hsiao (2005).

${ }^{4}$ See, e.g., Sartoris and Hill (1983).

${ }^{5}$ See, e.g., Maness and Zietlow (2005), Gitman (2006) and Stickney and Brown (1999).

${ }^{6}$ See for example earlier papers of Schiff and Lieber, (1974) and Kim and Chung (1990) and recent study by Bolton et al. (2011).

7 See, e.g., the pioneering work about cash management models developed by Baumol (1952), Miller and Orr (1966), Stone (1972), and more recent studies about the determinants of cash holdings by Mulligan (1997), Kim et al. (1998) ,Bates et al., (2009) and Almeida et al. (2014).

${ }^{8}$ A subset of these papers includes Lewelle and Edmister (1973), Lieber and Orgler (1975), Ferris (1981), Gentry and De La Garza (1985), Gallinger and Infflander (1986), Kim and Atkins (1978), Mian and Smith (1992), Barrot (2016) and McGuinness et al. 2018

9 Zipkin (2000) presents a complete treatment of inventory theory and developments of inventory management for use in Operations research and Operations management.

10 See for example Van Horne (1968), Yardeni (1978), Morris (1983), Sartoris and Hill (1983), Gentry and Lee (1986), Courakis (1988),Arcelus and Srinivasan (1994), Chung and Lin (1998).

11 A theoretical model developed by Markowitz (1952). Portfolio theory addresses the problem of the best choice of financial placements when they are characterized by a volatility of expected returns and risk. In order to approach the solution to Markowitz's problem, some assumptions about investor behavior and the characteristics of the investment categories that are taken into account to solve the problem of best choice should apply. These features were basically the following:

- Investors consider that the performance of each asset that is carried out over a specific period is described by a random variable that follows the normal distribution.

- Portfolio risk is represented and estimated by the expected return variability.

- Given the assumption of the normal distribution, the expected return is the average of the historical returns, while the risk is represented by the variance or, consequently, by the standard deviation of the expected returns. These features (return and risk) are known to all investors.

- Investors, although wishing to increase their wealth, are risk averse.

- Investor decisions are based on the relationship between the expected return and the estimated risk of returns, based on the assumption that a given level of risk should yield the best possible return or, alternatively, the risk level should be minimized for a given expected return.

A comprehensive introduction of the Markowitz Theory can be found, for example, in Elton, Gruber, Brown and Goetzmann (2003). 
${ }^{12}$ A portfolio is mean-variance efficient if it maximizes the expected return among all other portfolios that have the same standard deviation of returns or minimizes the standard deviation of returns among all those that have the same expected return; see, e.g., Gupta, F. and Eichhorn (1998). This process determines the appropriate asset allocation of the portfolio elements (the process of combining various assets classes in a portfolio to achieve the desired return).

13 See Elton, Gruber, Brown and Goetzmann (2003) for an outline of the mean-variance application or, e.g., Chiang and Wainwright (2005) for the mathematically derived theory.

14 The cash conversion cycle represents the net time interval of cash expenditures on firm operating resources and the cash receipts of operating revenues (Richards \& Laughlin, 1986). 